\title{
Paracentral Acute Middle Maculopathy Associated with Different Clinical Entities: A Case Series
}

\author{
(D) Gülşah Gümüş, (D) Şehnaz Özçalışkan, (D) Neşe Alagöz, (D) Beril Tülü Aygün, (D) Cengiz Alagöz, (D) Özgür Artunay \\ University of Health Sciences Turkey, İstanbul Beyoğlu Eye Training and Research Hospital, Clinic of Ophthalmology, Istanbul, Turkey
}

\section{Abstract}

Paracentral acute middle maculopathy (PAMM) implies the retinal lesions with hyperreflective inner nuclear layer (INL) changes in the spectral-domain optical coherence tomography (SD-OCT). PAMM occurs as a result of a flow deficit in the deep capillary plexus of the retina, with a prognosis depending on the associated retinal disease. This case series aimed to report the clinical findings of those diagnosed with PAMM and define the risk factors and associated pathologies. Medical records of patients diagnosed with PAMM between 2016 and 2019 in our hospital were reviewed. Detailed ophthalmologic examination and multimodal imaging were performed in all patients during the initial and follow-up visits. A total of 10 eyes from 9 patients were evaluated. The hyperreflective band-like lesion in the INL was observed in the SD-OCT imaging in all patients. The best-corrected visual acuities ranged between 20/20 and 20/1250. The idiopathic disorder was evaluated in 3 cases, 2 cases were secondary to central retinal artery occlusion, 1 case was secondary to retinal artery branch occlusion, 1 case was secondary to cilioretinal artery occlusion, 1 case was secondary to Susac syndrome, and 1 case was PAMM after pars plana vitrectomy. PAMM may be idiopathically seen without systemic diseases. Systemic research should be conducted for particularly systemic vascular risk factors when PAMM is detected. The prognosis of PAMM depends on the associated retinal pathology. Idiopathic cases generally have favorable visual outcomes, but severe vision loss occurs in other cases, such as PAMM secondary to retinal arterial pathologies.

Keywords: Multimodal imaging, paracentral acute middle maculopathy, retinal vascular disease, spectral-domain optical coherence tomography

\section{INTRODUCTION}

Paracentral acute middle maculopathy (PAMM) is a clinical entity characterized by hyperreflective band-like lesions in the spectraldomain optical coherence tomography (SD-OCT) at the inner nuclear layer (INL) and outer-plexiform layer (OPL). The disease may either be idiopathic or usually associated with retinal vascular pathologies $(1,2)$. With the advent of optic coherence tomography angiography (OCTA), PAMM occurs as a result of a flow deficit in the deep capillary plexus of the retina (1).

This case series aimed to report the cases diagnosed with PAMM and define the risk factors and associated pathologies.

\section{CASE PRESENTATIONS}

Medical records of patients diagnosed with PAMM between 2016 and 2019 in a tertiary referral center were reviewed. Ten eyes from 9 patients diagnosed with PAMM were included in this case series (Table 1). All patients had a complete ophthalmologic examination, including the best-corrected visual acuity (BCVA) with a Snellen chart, slit-lamp biomicroscopy, and intraocular pressure (IOP) measurements using the Goldmann applanation tonometry and fundus examination after dilatation at baseline and follow-up visits. Patients underwent color fundus, fluorescein angiography (FA) imaging (Canon CX-1digital retinal camera MYD/NM), SD-OCT, and near-infrared (NIF) imaging (Spectralis; 


\begin{tabular}{|c|c|c|c|c|c|c|c|c|c|}
\hline No & $\begin{array}{l}\text { Age/ } \\
\text { gender }\end{array}$ & Side & $\begin{array}{l}\text { Systemic } \\
\text { disease/risk } \\
\text { factors }\end{array}$ & $\begin{array}{l}\text { Complaint at } \\
\text { presentation }\end{array}$ & $\begin{array}{l}\text { Initial } \\
\text { BCVA }\end{array}$ & $\begin{array}{l}\text { Initial fundus } \\
\text { finding }\end{array}$ & Initial SD-OCT & Initial FFA & $\begin{array}{l}\text { Final } \\
\text { BCVA }\end{array}$ \\
\hline 1 & $38 / \mathrm{M}$ & OS & $\begin{array}{l}10 \text { years of } \\
\text { smoking }\end{array}$ & $\begin{array}{l}\text { Paracentral } \\
\text { scotoma }\end{array}$ & $20 / 20$ & $\begin{array}{l}\text { The gray-white } \\
\text { lesion with } \\
\text { prominent borders } \\
\text { in the superior } \\
\text { fovea }\end{array}$ & $\begin{array}{l}\text { Hyperreflective } \\
\text { band-like lesion } \\
\text { in the INL in the } \\
\text { superior fovea }\end{array}$ & $\begin{array}{l}\text { Arterial and } \\
\text { usual vein } \\
\text { filling }\end{array}$ & $20 / 20$ \\
\hline 2 & $28 / F$ & OS & - & $\begin{array}{l}\text { Inferior altutidinal } \\
\text { scotoma }\end{array}$ & $20 / 20$ & $\begin{array}{l}\text { The gray-white } \\
\text { lesion with } \\
\text { prominent borders } \\
\text { extending from the } \\
\text { superior fovea to } \\
\text { the superior optic } \\
\text { disc }\end{array}$ & $\begin{array}{l}\text { Hyperreflective } \\
\text { band-like lesion } \\
\text { in the INL in the } \\
\text { superior fovea }\end{array}$ & $\begin{array}{l}\text { Arterial and } \\
\text { usual vein } \\
\text { filling }\end{array}$ & $20 / 20$ \\
\hline 3 & $58 / \mathrm{M}$ & OS & - & $\begin{array}{l}\text { Paracentral } \\
\text { scotoma }\end{array}$ & $20 / 20$ & $\begin{array}{l}\text { A pale area in } \\
\text { the superior } \\
\text { papillomacular } \\
\text { bundle }\end{array}$ & $\begin{array}{l}\text { Hyperreflective } \\
\text { band-like lesion } \\
\text { in the INL in the } \\
\text { superior macula }\end{array}$ & $\begin{array}{l}\text { Arterial and } \\
\text { usual vein } \\
\text { filling }\end{array}$ & $20 / 20$ \\
\hline 4 & $70 / \mathrm{F}$ & OS & $\begin{array}{l}\text { CAD, carotid } \\
\text { artery stenosis }\end{array}$ & Sudden vision loss & $20 / 1250$ & $\begin{array}{l}\text { Diffuse retinal } \\
\text { whitening }\end{array}$ & $\begin{array}{l}\text { A diffuse } \\
\text { hyperreflective } \\
\text { band-like lesion } \\
\text { in the INL in the } \\
\text { macula }\end{array}$ & $\begin{array}{l}\text { Delay in } \\
\text { central } \\
\text { retinal artery } \\
\text { filling and } \\
\text { elongation in } \\
\text { arteriovenous } \\
\text { transit time }\end{array}$ & $20 / 1250$ \\
\hline 5 & $53 / F$ & OD & HT & Sudden vision loss & $20 / 1250$ & $\begin{array}{l}\text { Diffuse retinal } \\
\text { whitening }\end{array}$ & $\begin{array}{l}\text { A diffuse } \\
\text { hyperreflective } \\
\text { band-like lesion } \\
\text { in the INL in the } \\
\text { macula }\end{array}$ & $\begin{array}{l}\text { Delay in } \\
\text { central retinal } \\
\text { artery filling }\end{array}$ & $20 / 1250$ \\
\hline 6 & $40 / \mathrm{F}$ & OD & - & Misty vision & $20 / 20$ & $\begin{array}{l}\text { Edema in the } \\
\text { nerve fiber layer } \\
\text { extending from } \\
\text { the papillomacular } \\
\text { bundle to the } \\
\text { inferior macula }\end{array}$ & $\begin{array}{l}\text { Hyperreflective } \\
\text { band-like lesion } \\
\text { in the INL and } \\
\text { OPL in the } \\
\text { papillomacular } \\
\text { bundle }\end{array}$ & $\begin{array}{l}\text { Delay in the } \\
\text { filling of the } \\
\text { cilioretinal } \\
\text { artery }\end{array}$ & $20 / 20$ \\
\hline 7 & $61 / \mathrm{M}$ & OS & HT & $\begin{array}{l}\text { Decreased } \\
\text { vision and } \\
\text { metamorphopsia }\end{array}$ & $20 / 32$ & $\begin{array}{l}\text { Edema in the } \\
\text { nerve fiber layer } \\
\text { extending from the } \\
\text { superior temporal } \\
\text { vein arch to the } \\
\text { macula }\end{array}$ & $\begin{array}{l}\text { Hyperreflective } \\
\text { band-like lesion } \\
\text { in the INL and } \\
\text { OPL }\end{array}$ & $\begin{array}{l}\text { Slight delay } \\
\text { in left upper } \\
\text { temporal } \\
\text { artery branch } \\
\text { filling }\end{array}$ & - \\
\hline 8 & $28 / \mathrm{F}$ & Bilateral & $\begin{array}{l}\text { Hearing loss, } \\
\text { headache, } \\
\text { encephalopathy }\end{array}$ & $\begin{array}{l}\text { Bilateral vision } \\
\text { loss }\end{array}$ & $\begin{array}{l}\text { OD: } 20 / 50 \\
\text { OS: } \\
\text { 20/100 }\end{array}$ & $\begin{array}{l}\text { OD: faint optic } \\
\text { disc and whitening } \\
\text { area with } \\
\text { microangiopathic } \\
\text { lesions in the fovea } \\
\text { OS: } \\
\text { microangiopathic } \\
\text { lesions in the } \\
\text { fovea and sub-ILM } \\
\text { hemorrhage } \\
\text { in the inferior fovea }\end{array}$ & $\begin{array}{l}\text { OD: } \\
\text { Hyperreflective } \\
\text { band-like lesions } \\
\text { in INL } \\
\text { OS: Sub-ILM } \\
\text { hemorrhage and } \\
\text { hyperreflective } \\
\text { band-like lesion } \\
\text { in the INL } \\
\text { around the sub- } \\
\text { ILM hemorrhage }\end{array}$ & $\begin{array}{l}\text { bilaterally } \\
\text { small } \\
\text { arteriolar } \\
\text { obstructions } \\
\text { and } \\
\text { peripheral } \\
\text { ischemic areas }\end{array}$ & $\begin{array}{l}\text { OD: } 4 / 50 \\
\text { OS: } 20 / 63\end{array}$ \\
\hline 9 & $76 / \mathrm{M}$ & OS & $\mathrm{DM}, \mathrm{CAD}$ & $\begin{array}{l}\text { Paracentral } \\
\text { scotoma }\end{array}$ & $20 / 1250$ & $\begin{array}{l}\text { Gray-white lesion } \\
\text { located deep in the } \\
\text { paracentral fovea }\end{array}$ & $\begin{array}{l}\text { Hyperreflective } \\
\text { band-like lesion } \\
\text { in the INL in } \\
\text { the paracentral } \\
\text { fovea }\end{array}$ & & $20 / 1250$ \\
\hline
\end{tabular}


Heidelberg Engineering), and three patients had OCTA imaging with Cirrus 5000 HD OCT with AngioPlex OCT Angiography device.

\section{Cases 1-3}

The systemic workup was negative in 3 cases (cases 1, 2, and 3), without signs of retinal vascular diseases. Therefore, participants were classified as idiopathic PAMM. The only risk factor for vascular diseases was smoking for 10 years in case 3 . At presentation, paracentral scotoma was the common finding among these cases, with a BCVA of 20/20 in the affected eyes. Fundus evaluation revealed a gray-white lesion with prominent borders, and the SD-OCT demonstrated a typical hyperreflective band-like lesion in the INL. The FA was unremarkable in 3 patients, and the OCTA showed reduced deep capillary flow in case 2. At the end of the follow-up, the BCVA was stable with middle retinal layer thinning on the SD-OCT (Figure 1).

\section{Cases 4 and 5}

Cases 4 and 5 presented to our clinic with a sudden vision loss in one eye and both with a BCVA of 20/1250. Case 4 had a history of coronary artery bypass graft surgery 2 weeks ago and case 5 had hypertension (HT) that was controlled with medications.
Fundus examination and FA imaging demonstrated a central retinal artery occlusion (CRAO) in both patients, whereas a diffuse hyperreflective band-like lesion in the INL was observed in the SD-OCT. Further systemic evaluation of case 4 revealed severe carotid stenosis (80-90\%). At month 6, the BCVA of both patients was stable with diffuse macular thinning in the SD-OCT (Figure 2).

\section{Case 6}

A 40-year-old female complained of blurred vision in her right eye. Her past medical history was unremarkable, and the BCVA was 20/20 bilaterally. The fundus examination revealed a retinal thickening from the papillomacular bundle to the inferior macular region in her right eye. The NIF imaging revealed a dark-gray lesion at the corresponding area of the lesion. The FA showed a delay in filling of the right cilioretinal artery. The SD-OCT showed a hyperreflective band-like lesion in the INL and OPL in the region consistent with the lesion. The patient was referred to internal medicine for systemic workup, and her hypercoagulability tests were positive for factor $\mathrm{V}$ Leiden mutation.

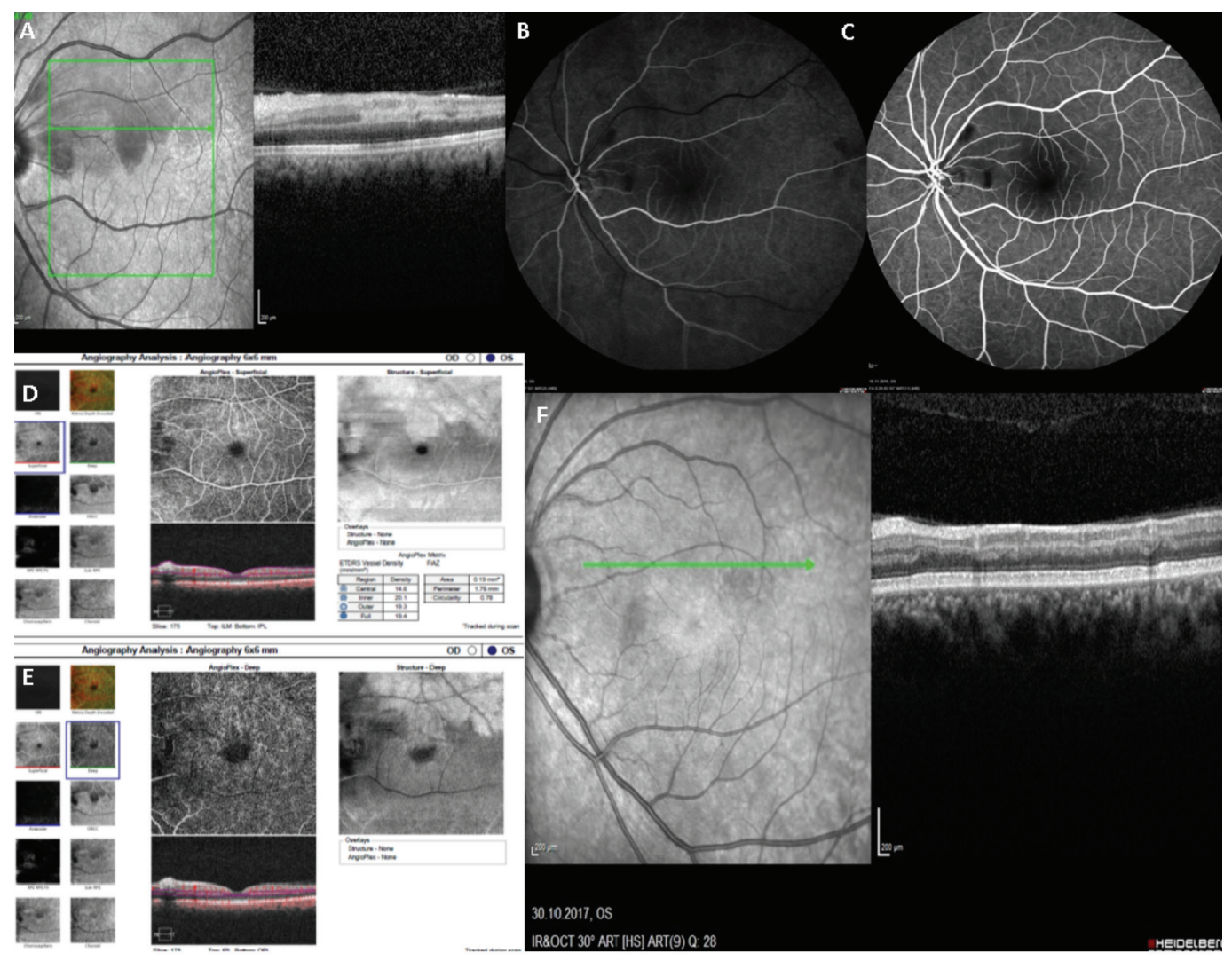

Figure 1. Case 2: (A) Initial SD-OCT shows a hyperreflective band-like lesion in the INL. (B) Initial FA shows a normal filling in 15 min. (C) Initial FA shows a normal filling in 30 min. (D) Initial OCTA shows a normal superficial capillary plexus flow. (E) Initial OCTA shows a decreased flow of the deep capillary plexus. (F) SD-OCT at 6 months shows a middle retinal layer thinning

SD-OCT: Spectral-domain optical coherence tomography, INL: Inner nuclear layer, FA: Fluorescein angiography, OCTA: Optic coherence tomography angiography 


\section{Case 7}

A 61-year-old male presented with decreased vision and metamorphopsia in his left eye for 1 week. His past medical history was unremarkable, except for the HT that was controlled with medication. His BCVA was 20/32 in his left eye. The fundus examination of the left eye showed a retinal nerve fiber layer swelling, extending throughout the superior temporal vein arch, surrounding the macula. The NIF demonstrated darkgray lesions and the FA showed a slight delay in the left upper temporal artery branch filling. A hyperreflective band-like lesion was observed in the INL and OPL in the region corresponding to the lesion in the SD-OCT. The patient was diagnosed with PAMM secondary to retinal artery branch occlusion.

\section{Case 8}

A 28-year-old female patient presented with decreased vision in both eyes. The patient suffered from hearing loss and severe headaches for 2 years. Her ophthalmologic evaluation revealed a BCVA of 20/50 in her right eye and 20/100 in the left. Fundus examination of the right eye revealed a pallor optic disk, with white microangiopathic lesions around the fovea. Perifoveal microangiopathic lesions and macular sub-internal limiting membrane (sub-ILM) hemorrhage were also detected in her left eye. The NIF imaging revealed a grayish lesion in the inferior perifoveal region bilaterally. The FA showed small arteriolar obstructions and peripheral ischemic areas in both eyes. The SD-OCT revealed bilateral hyperreflective band-like lesions in the INL, with accompanying sub-ILM hemorrhage in her left eye. She was referred to neurology and diagnosed with Susac syndrome. She was treated with intravenous corticosteroid and methotrexate by the neurologists. After 6 months, her BCVA was 20/50 and 20/63, in her right and left eyes, respectively. The SD-OCT revealed a bilateral thinning of the affected layers in the corresponding region to the lesions and retinal pigment epithelial (RPE) atrophy in the left eye (Figure 3).

\section{Case 9}

A 76-year-old male patient presented with visual disturbances and metamorphopsia in his left eye. His medical history was positive for coronary artery disease (CAD) and diabetes mellitus (DM). He had a coronary artery bypass graft surgery 6 years ago. The BCVA was 20/200 on his left eye. Fundus examination revealed an epiretinal membrane (ERM) and posterior vitreous detachment in his left eye. The SD-OCT imaging showed vitreomacular traction concurring with an ERM. He had pars

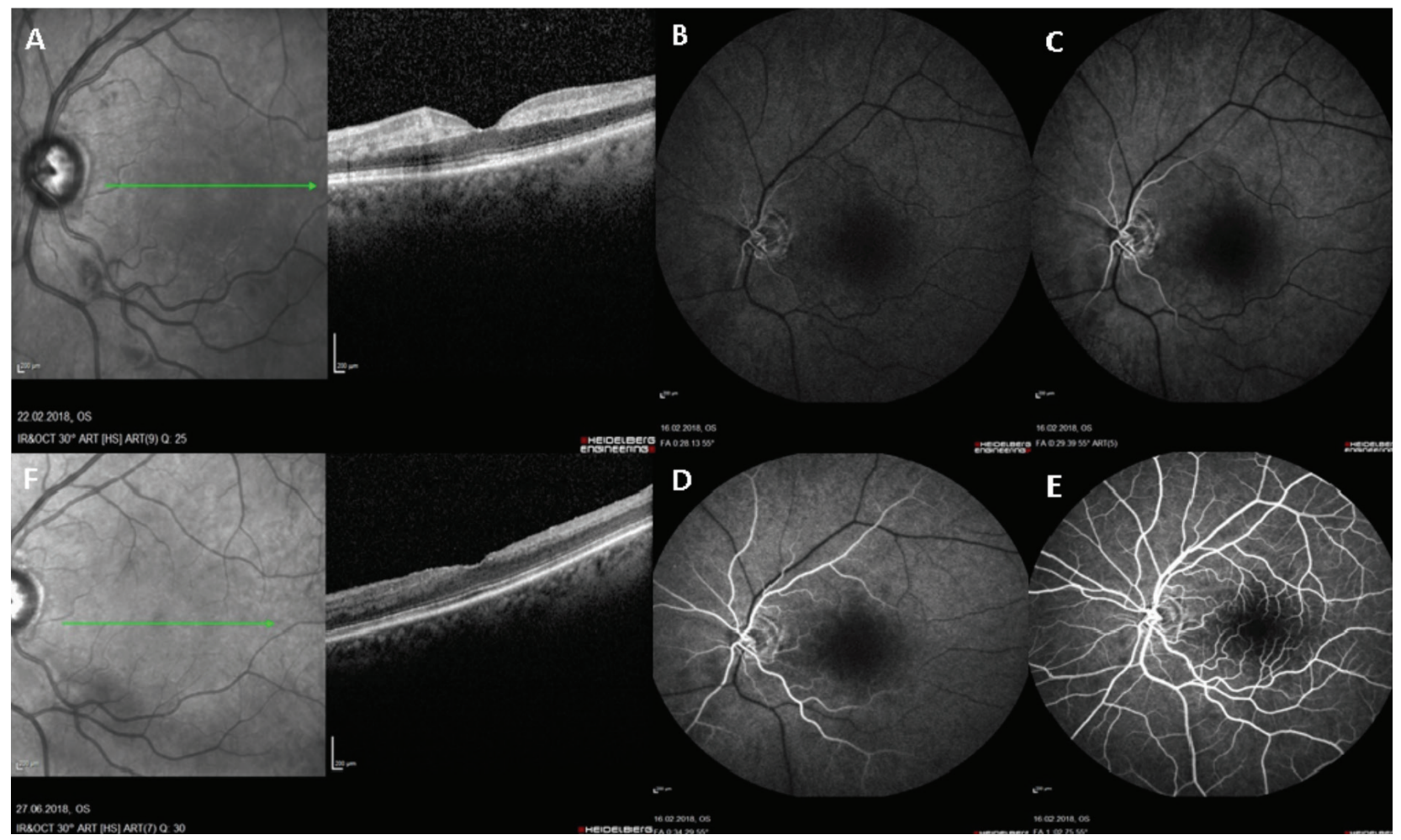

Figure 2. Case 4: (A) Initial SD-OCT shows a diffuse hyperreflective band-like lesion in the INL. (B) Initial FA shows delayed perfusion of CRA in 28 S. (C) Initial FA shows delayed perfusion of the CRA in $30 \mathrm{~s}$. (D) Initial FA shows a delayed filling of the CRA in 34 s. (E) Initial FFA in 1 min. (F) SD-OCT in 6 months shows a diffused macular thinning

SD-OCT: Spectral-domain optical coherence tomography, INL: Inner nuclear layer, FA: Fluorescein angiography, CRA: Central retinal artery, FFA: Fundus fluorescein angiography 
plana vitrectomy (PPV) surgery, with ERM and ILM peeling and air tamponade in his left eye.

The patient described a paracentral scotoma in the left eye 1 week postoperatively, with a BCVA of 20/800. The fundus examination revealed a grayish-white lesion located deeply in the paracentral fovea of the left eye. The NIF imaging revealed a gray-white lesion corresponding to the region of the lesion. A hyperreflective band-like lesion in the INL was observed on the SD-OCT. The patient was considered as PAMM development following PPV. At 6 months postoperatively, the BCVA in his left eye was improved to 20/50. The middle retinal layers of the corresponding region showed marked thinning in the macular SD-OCT (Figure 4).

\section{DISCUSSION}

PAMM is characterized by hyperreflective band-like lesions in the INL in the SD-OCT and a hyporeflective lesion in the NIF in the acute phase. In the chronic phase, a middle retinal layer thinning is observed in the corresponding region to the lesion (3). Rahimy et al. (1) described PAMM as a clinical entity rather than a disease. Currently, no treatment modality has been defined for PAMM. A complete systemic workup for risk factors is recommended during diagnosis.

PAMM is a clinical finding that occurs with the occlusion of the intermediate capillary plexus and deep capillary plexus (3). Consider imaging techniques when PAMM is suspected is essential, since PAMM may often be missed during clinical evaluation. SDOCT and NIF are the most useful imaging methods in PAMM

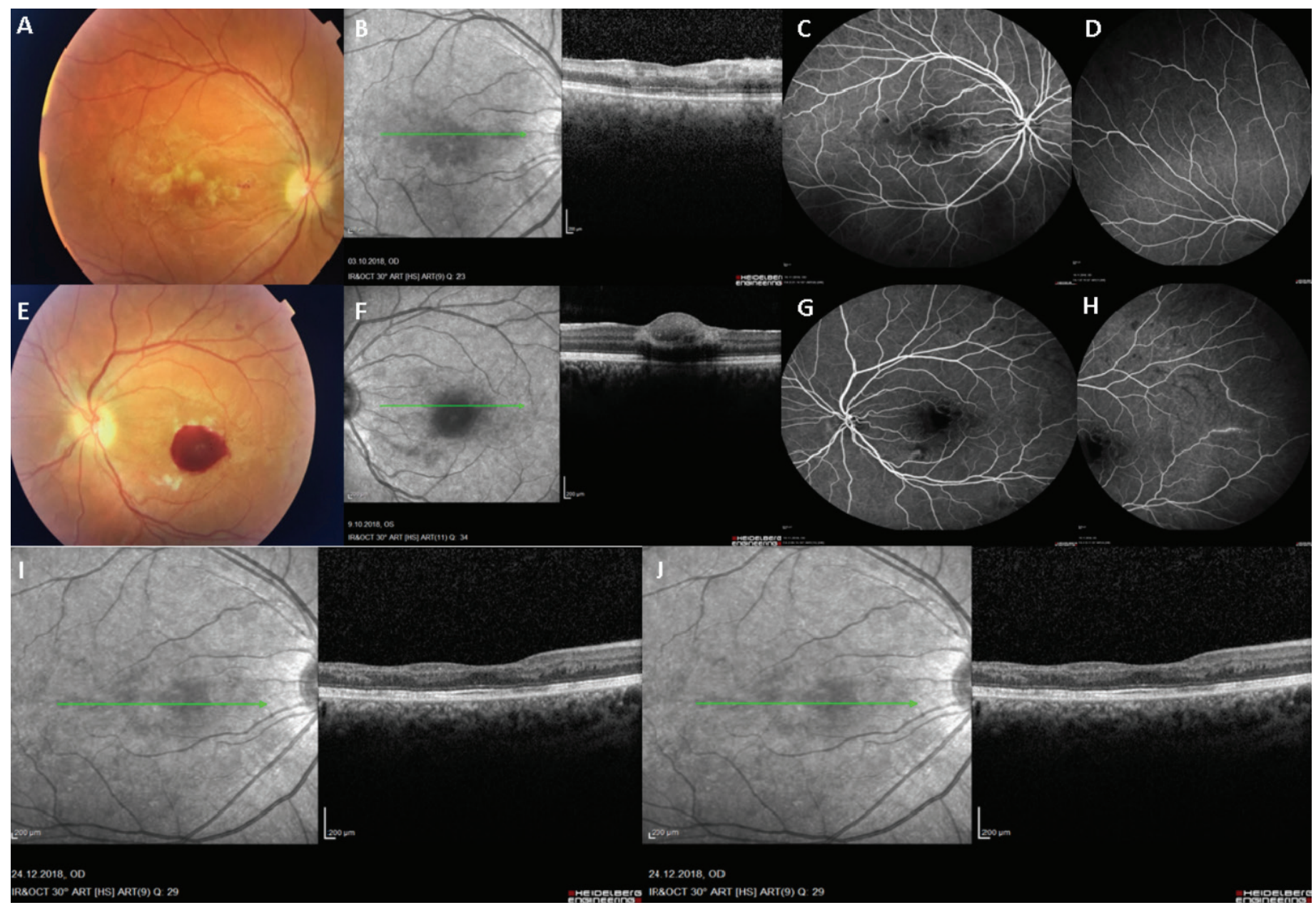

Figure 3. Case 8: (A) Initial right eye fundus photo shows a pallor optic disk, with white microangiopathic lesions around the fovea. (B) Initial right eye SD-OCT shows hyperreflective band-like lesions. (C) Right eye FA shows central arteriolar occlusion. (D) Right eye FA shows peripheral ischemic areas. (E) Initial left eye fundus photo shows perifoveal microangiopathic lesions and macular sub-ILM hemorrhage. (F) Initial left eye SD-OCT shows hyperreflective band-like lesions in INL and sub-ILM with hemorrhage in these lesions. (G) Left eye FA shows central arteriolar occlusion. (H) Left eye FA shows peripheral ischemic areas. (I) Right eye SD-OCT at 8 months shows thinning of the affected layers in the corresponding region of the lesions. (J) Left eye SD-OCT at 8 months shows thinning of the affected layers in the corresponding region of the lesions and RPE atrophy SD-OCT: Spectral-domain optical coherence tomography, FA: Fluorescein angiography, sub-ILM: Sub-internal limiting membrane, INL: Inner nuclear layer, RPE: Retinal pigment epithelial 
diagnosis. Moreover, OCTA is another novel imaging method that visualizes the retinal vascular structures, thus detecting retinal pathologies (1). The FA is insufficient in PAMM diagnosis but is important for differential diagnosis. The association between the retinal vascular disorders and PAMM, as well as idiopathic cases, was reported in the literature (3). In addition, cases with PAMM secondary to systemic vasoconstrictive conditions were previously reported $(2,4,5)$.

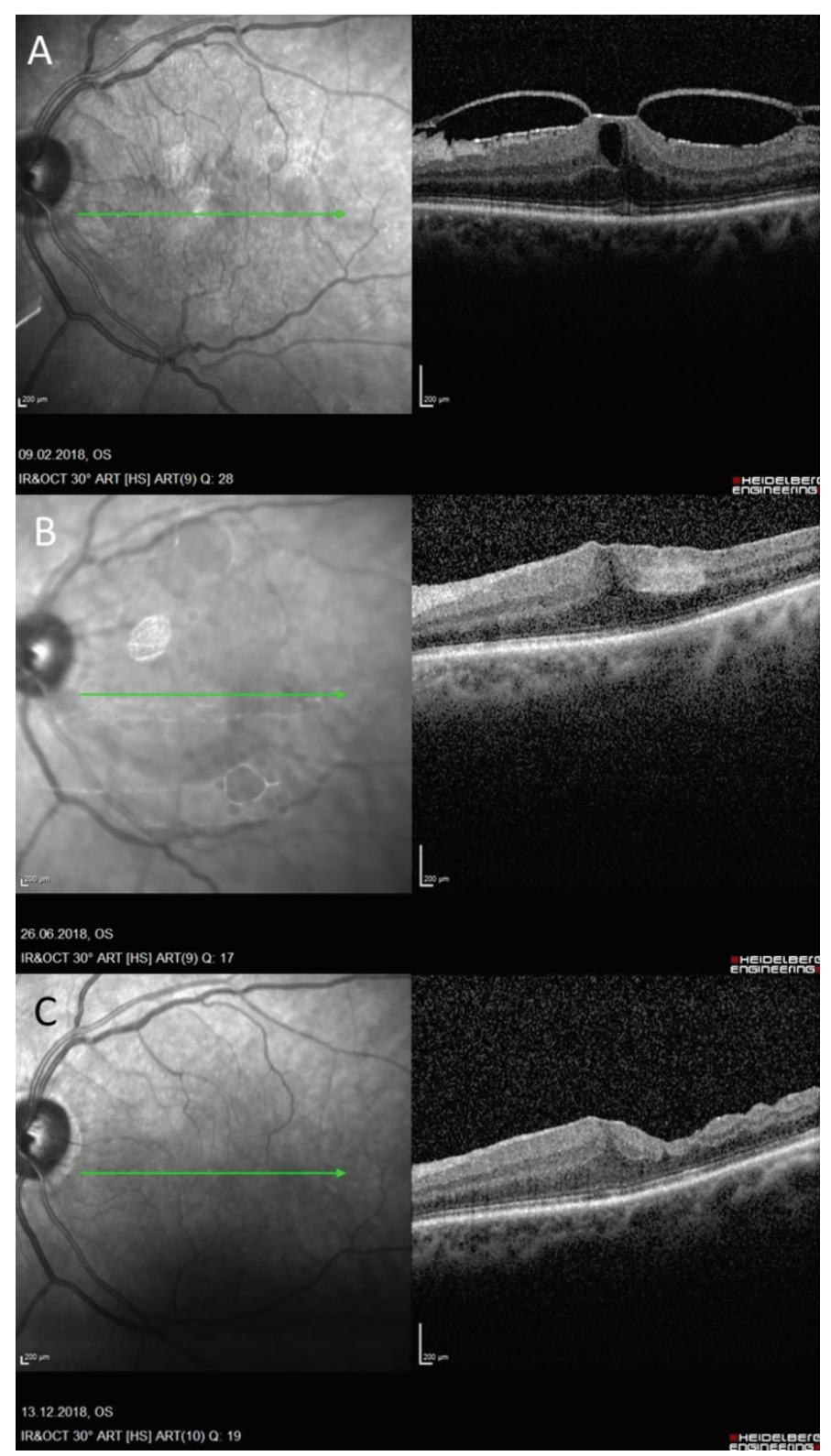

Figure 4. Case 9: Preoperative SD-OCT demonstrating an epiretinal membrane extending to the inner retinal layers and vitreomacular traction (A). SD-OCT at postoperative 1 week (B). A clear parafoveal hyperreflective band with distinct margins in the inner nuclear layer. SD-OCT at postoperative 6 months (C). Retinal atrophy involves the inner layers in the temporal region of the macula SD-OCT: Spectral-domain optical coherence tomography
PAMM can be idiopathically observed, even in young cases, without systemic and ocular risk factors $(1,6,7)$. Several cases were reported as idiopathic PAMM in previous literature. The age range of idiopathic cases in the literature varies between 16 and 65 years (8). In idiopathic cases, the typical finding is a paracentral scotoma, which may also be accompanied by decreased vision. In most idiopathic PAMM cases, visual acuity is usually preserved, whereas paracentral scotoma becomes permanent during follow-ups (8). In our series, cases 1, 2, and 3 were considered as idiopathic due to insufficient systemic and vascular risk factors or ocular pathology coexistence. All idiopathic cases were relatively younger than other cases, and visual acuity was better both at presentation and during follow-ups. However, the paracentral scotoma became permanent in these patients. Possible causes of idiopathic PAMM include factors that cause small blood vessel constriction and coagulation disorders, such as HT, sympathetic excitement, hyperlipidemia, DM, pregnancy, arteritis, and systemic lupus erythematosus $(1,8)$. Any risk factors for systemic inquiry in idiopathic patients were not defined, except for a positive history of smoking, in one case.

PAMM related to CRAO in cases 4 and 5 were reported. CRAO should be considered in patients with diffuse PAMM, even with normal clinical and angiographic findings (1). Yu et al. (9) reported cases with isolated diffuse PAMM due to CRAO. The absence of filling defect in the FA that was observed in some of these cases may be due to rapid recanalization in the CRA. These cases had severe vision loss consistent with CRAO. Similar to previous reports, our cases had a BCVA of 20/1250 at presentation. Both cases had diffuse PAMM in the SD-OCT and a filling defect in CRA in the FA.

Rahimy et al. (1) reported that detailed clinical evaluation with multimodal imaging is essential in the differential diagnosis of branch retinal artery occlusion (BRAO) and CRAO, even without evidence for arterial occlusion in the fundus examination of PAMM cases. The FA revealed a delay in filling of the cilioretinal artery in case 6 and BRA in case 7. Decreased BCVA was not severe in these cases; however, PAMM lesions covered a relatively large area in the NIF and SD-OCT.

Susac syndrome is an occlusive arteriolar disease and is thought of as an autoimmune reaction to an unknown antigen. The disease causes vasoocclusion in the vessels of the brain, ear, and retina $(10,11)$. Patients are usually diagnosed in the $3^{\text {rd }}-4^{\text {th }}$ decade with female preponderance. Brain involvement, such as encephalopathy, focal neurological deficits and headaches, hearing loss, and retinal arterial occlusions is the pathognomonic triad. Retinal involvement includes focal segmental staining in the arterial wall in the FA and sectoral damage in the internal 
retinal layers from the retinal nerve fiber layer to the OPL in the SD-OCT (11). In our PAMM case diagnosed with Susac syndrome, the FA showed focal arteriolar occlusion areas and peripheral retinal ischemia.

Case 9, a patient with CAD and DM, was diagnosed with PAMM after PPV. Increased IOP and use of subtenon, peribulbar, or retrobulbar anesthesia during an ocular surgery may alter the ocular perfusion, thus causing vascular occlusion (12). Systemic diseases, such as DM, HT, CAD, and hyperlipidemia, are also risk factors for vascular occlusion. The development of BRAO and CRAO was reported in the literature after cataract surgery, PPV, scleral buckle surgery, intravitreal anti-vascular endothelial growth factor injections, and glaucoma valve implantation (1214). This case is the first PAMM case in the literature described after vitrectomy since the middle retinal layers are more vulnerable to ischemia (2). The presence of risk factors, such as increased IOP, local retinal layer damages, and capillary plexuses in these layers during a retinal surgery might explain the PAMM development in our case.

\section{CONCLUSION}

Retinal imaging is essential in patients with visual disturbances that cannot be diagnosed with clinical examination alone. Patients suspected of PAMM should be investigated using SD-OCT imaging, even without FA findings. PAMM should be considered as idiopathic, even in young adults without systemic diseases. When PAMM is detected, systemic research should be conducted for systemic vascular risk factors. The PAMM prognosis depends on the associated conditions. Idiopathic cases usually have favorable outcomes and other PAMM cases may suffer severe vision loss. The hyperreflective bands on the SD-OCT are replaced with INL atrophy over time; however, the paracentral scotoma usually becomes permanent.

\section{Ethics}

Informed Consent: Written informed consent was obtained from all patients for publication of this case report and accompanying images.

Peer-review: Externally peer-reviewed.

\section{Authorship Contributions}

Surgical and Medical Practices: G.G., S..Ö., C.A., Ö.A., Concept: S.Ö., N.A., B.T.A., Design: N.A., B.T.A., Data Collection or Processing: G.G., B.T.A., C.A., Ö.A., Analysis or Interpretation: G.G., Literature Search: G.G., Writing: G.G., S..Ö., N.A.
Conflict of Interest: No conflict of interest was declared by the authors.

Financial Disclosure: The authors declared that this study received no financial support.

\section{REFERENCES}

1. Rahimy E, Kuehlewein L, Sadda SR, Sarraf D. Paracentral acute middle maculopathy: what we knew then and what we know now. Retina 2015:35:1921-30

2. Chen X, Rahimy E, Sergott RC, Nunes RP, Souza EC, Choudhry N, et al. Spectrum of retinal vascular diseases associated with paracentral acute middle maculopathy. Am J Ophthalmol 2015;160:26-34.e1.

3. Yu S, Wang F, Pang CE, Yannuzzi LA, Freund KB. Multimodal imaging findings in retinal deep capillary ischemia. Retina 2014;34:636-46.

4. Sarraf D, Rahimy E, Fawzi AA, Sohn E, Barbazetto I, Zacks DN, et al. Paracentral acute middle maculopathy: a new variant of acute macular neuroretinopathy associated with retinal capillary ischemia. JAMA Ophthalmol 2013;131:1275-87.

5. Fawzi AA, Pappuru RR, Sarraf D, Le PP, McCannel CA, Sobrin L, et al. Acute macular neuroretinopathy: long-term insights revealed by multimodal imaging. Retina 2012;32:1500-13.

6. Rahimy E, Sarraf D, Dollin ML, Pitcher JD, Ho AC. Paracentral acute middle maculopathy in nonischemic central retinal vein occlusion. Am J Ophthalmol 2014;158:372-80.e1.

7. Rahimy E, Sarraf D. Paracentral acute middle maculopathy spectraldomain optical coherence tomography feature of deep capillary ischemia. Curr Opin Ophthalmol 2014;25:207-12.

8. Chen Y, Hu Y. The optical imaging of idiopathic paracentral acute middle maculopathy in a Chinese young man and review of the literature. Photodiagnosis Photodyn Ther 2017;19:383-87.

9. Yu S, Pang CE, Gong Y, Freund KB, Yannuzzi LA, Rahimy E, et al. The spectrum of superficial and deep capillary ischemia in retinal artery occlusion. Am J Ophthalmol 2015;159:53-63.e1-2.

10. Dörr J, Krautwald S, Wildemann B, Jarius S, Ringelstein M, Duning T, et al. Characteristics of Susac syndrome: a review of all reported cases. Nat Rev Neurol 2013;9:307-16.

11. Kleffner I, Dörr J, Ringelstein M, Gross CC, Böckenfeld Y, Schwindt W, et al. Diagnostic criteria for Susac syndrome. J Neurol Neurosurg Psychiatry 2016;87:1287-95.

12. Fischer C, Bruggemann A, Hager A, Callizo Planas J, Roider J, Hoerauf $\mathrm{H}$. Vascular occlusions following ocular surgical procedures: a clinical observation of vascular complications after ocular surgery. J Ophthalmol 2017;2017:9120892.

13. Kumar A, Agarwal D, Balaji A. Commentary: a cluster of central retinal artery occlusions following cataract surgery. Indian J Ophthalmol 2019;67:635

14. Lin FY, Fu MS. Central retinal artery occlusion after uneventful glaucoma valve implantation surgery with retrobulbar anesthesia: a case report. Int J Ophthalmol 2019;12:1362-5. 